\title{
Calibration of Nitrogen Content of Soil with Sweet Corn
}

\author{
I. BUZÁS, E. HOYK, I. CSERNI and J. BORS-PETÖ
}

Kecskemét College, Institute of Environmental Science, Kecskemét (Hungary)

The nutrient requirement of plants is expressed by the quantity of the necessary nutritive element, its absorption and uptake curve, uptake dynamics. If the soil is incapable of sufficing the targeted yield's nutrient requirement, it is necessary to raise the nutrient supply. This usually does not mean increasing the nutrient quantity found in soil, because the soil practically always contains much more nutritive elements than required by the plant. Technically it means the enhancement of the quantity of the nutritive element supplied during the plant's nutrient absorption phase - and as this nutrient quantity is to be supplied within a definite period - in fact it means intensifying the speed of the nutrient replenishment $(\mathrm{kg} / \mathrm{ha} / \mathrm{day})$.

A fertilizer recommendation system has two separate phases. The first is to determine what yield (quantity and quality-wise) the soil is capable of producing without fertilization ("diagnosis"). If the expected yield does not meet the targeted production goal because of the soil's inefficient or inappropriately distributed nutrient supply in time - and fertilization seems to be the most efficient way to correct it - the "therapy" can follow, i.e. fertilization.

The soil-fertilizer-plant relationship is more complicated than just adding available nutrients to the soil during fertilization that plants simply take up. Soil reacts with fertilizer. Fertilization is effective, if - as a result of fertilizer application - the soil supplies the nutrient more quickly than prior to it. In the course of fertilization the amount of available forms does not always grow considerably. E.g. after phosphorus fertilization - regardless of the applied phosphorus form - usually no more than the equivalent of $1 \mathrm{~kg} \mathrm{P}_{2} \mathrm{O}_{5} /$ ha phosphorus is in uptakeable form $\left(\mathrm{H}_{2} \mathrm{PO}_{4}{ }^{-}\right)$in the soil's ploughed layer, whereas plants take up the amount of $100 \mathrm{~kg}$ nutrients/ha.

Differences must be perceived in the quantity of nutritive elements: between the nutrient amount in the soil that can be taken up by the plant at a given time, and the nutrient amount the soil can be supplied with during the nutrient uptake period of the plant. The most important difference between the two quantities is that the first nutrient quantity can be defined, whereas the latter is not the soil's or the soil sample's available nutrient content, because it can only be interpreted in a given soilplant system and with regard to the length of the supply period. Despite the seemingly trivial distinction, researchers have been experimenting for a hundred years to find an extractor that extracts as much nutrient as the plant takes up (BUZÁS, 1987).

Correspondence to: ISTVÁN BUZÁS, Kecskemét College, Faculty of Horticulture, Institute of Environmental Science, H-6000 Kecskemét, Erdei F. tér 1-3. Hungary. E-mail: buzas.istvan@kfk.kefo.hu 
The nutrient quantity supplied by the soil cannot be measured. Only the soil's nutrient content is measurable, which on its own is insufficient for determining the required fertilizer amount. Therefore it is necessary to carry out fertilization trials for supporting fertilizer recommendation.

Nowadays we have primary access to the findings of fertilization long-term trials, during which the same amounts of nutrients are allocated every year (perhaps in various forms, combined with different agrotechnical procedures etc.).

In long-term fertilization trials, from the second year onwards the yield differences occurring on the differently treated plots cannot be considered as the result of the given year's treatment. After fertilization in the first year the soil's nutrient supply changes in comparison to the initial state. The longer such experiments are carried out, the farther we get from fertilizing practice; as the soil having the highest nutrient content - perhaps so much that triggers yield depression - is still treated with the biggest amount of fertilizer, whereas nothing is added to the soil lacking nutrients.

On the basis of the above-mentioned facts some questions arising from longterm fertilization trials are: e.g. in a given crop rotation at which fertilization treatment is the nutrient balance poised? In the case of a certain soil analysis result the yield has not increased as yet, and it is not known whether higher yields would have been reached if the large fertilizer dose had not been added to the plot (BuZÁs, 2002).

The soil analysis methods introduced for "measuring" the soil's nutrient supply only give a "sign", a dimensionless number, about which it is only known, or much rather assumed that it is in proportion to the soil's nutrient supply. After the test results a measurement unit is written (e.g. $\mathrm{mg} / \mathrm{kg}$ soil), but this does not give physical content to these values, it only enables the comparison of two such numbers.

Soil nutrient analysis results only gain physical meaning by being calibrated. The logic of calibrating soil nutrient analysis is the same as calibrating a sign provided by any other instrumental analytical method. In the course of instrumental analysis a calibrating solution series has to be made, a standard series with growing concentration. When calibrating soil analysis values, a soil series with growing nutrient supply has to be prepared.

The current recommendation systems can only be accepted temporarily as makedo; the soil analysis results cannot be considered scientifically valid without calibrating them with field trials.

Results directly utilizable in practice can be obtained if the calibration is carried out in small plots. The field should be chosen so that its nutrient supply, which calibration is targeted on, is low. After fertilization for one or several years plots have to be formed in which the nutrient supply to be calibrated varies from very poor to extreme, whereas the supply of all other nutrients is the same (abundant) on all of the plots. In the case of a soil analysis calibration method (or methods), the calibration can be considered achieved in respect of the given plant grown on the experimental plot, if the soil analysis values are represented in correlation with the quality, quantity and inner values, etc., namely, the data forming the production goal. 
In this way only the "diagnosis" phase of fertilizer recommendation can be reached. However, if big enough plots are formed, and with each soil analysis the differently supplied plots are divided into smaller plots and fertilized with the targeted nutrient using amounts ranging from zero to very large dose, the calibration required for "therapy" is carried out at the same time. Soil analysis results obtained on the big plot are to be presented in correlation with the achievement of the production goal. Thus, the accomplished calibration curve will show the fertilizer amount required for the targeted yield.

Naturally, the calibration attained by the experiments is only valid for the given soil type and in years with similar weather conditions. Calibration trials enable the separate study of the effect of soil supply and fertilization on the yield.

\section{Material and Methods}

Following a two-year pilot study the research was carried out in 2005 at the Kisfái Research Farm of the Kecskemét College on a calcareous sandy soil with sweetcorn plantation.

The sand, sandy loam textured $\left(\mathrm{K}_{\mathrm{A}}=25-35\right)$ soil, with alkaline $\mathrm{pH}\left(\mathrm{pH}_{\mathrm{H} 2 \mathrm{O}}=\right.$ 8.0-8.6) is calcareous from the surface. Its carbonate and humus contents are both $1.5 \%$. The groundwater table was found at the 5-6 m depth during the years of the trial. In general, the Great Hungarian Plain is poor in precipitation. Despite this, the precipitation between November 2004 and April 2005 was quite high $(200 \mathrm{~mm})$.

The soil's phosphorus and potassium supply falls into the well-supplied category (ANTAL et al., 1979). In the autumn prior to sowing a complex fertilizer was distributed on the site with active agent content of $42 \mathrm{~kg} \mathrm{P}_{2} \mathrm{O}_{5}, 48 \mathrm{~kg} \mathrm{~K}_{2} \mathrm{O}, 36 \mathrm{~kg} \mathrm{Mg}, 6$ $\mathrm{kg} \mathrm{Cu}, 1.5 \mathrm{~kg} \mathrm{Zn}$ and $\mathrm{Fe}$, and $0.6 \mathrm{~kg} \mathrm{~B}$ per hectare.

The trial was set up in a two-factor split-plot design with four repetitions. Factor "a" is the nitrogen supply of the soil, in other words, the nitrate content of the soil before fertilization. Factor " $b$ " is the amount of nitrogen given at spring in the form of ammonium nitrate.

The nitrogen supply (factor "a") of the main plot's (big plot) soil was set for various levels with the help of the ammonium nitrate fertilizer given in the autumn prior to sowing, with rates of $0,150,300$ and $450 \mathrm{~kg} \mathrm{~N} / \mathrm{ha}$. The nitrate content of the soil was measured on 26 April, 2005. Soil samples were collected from every 30 $\mathrm{cm}$ down to $90 \mathrm{~cm}$.

On this sandy soil - due to the relatively high precipitation in winter - the smallest difference occurred in the upper $30 \mathrm{~cm}$ of the soil due to the nitrate nitrogen treatment. Despite this, only the nitrate content of the upper layer and the corn yield show correlation, however, no correlation was found between the nitrate content of the lower layers and the yield. Because of this, factor "a" is the nitrate content of the $0-30 \mathrm{~cm}$ soil layer $\left(\mathrm{a}_{1}=2.9 ; \mathrm{a}_{2}=3.1 ; \mathrm{a}_{3}=3.2 ; \mathrm{a}_{4}=4.6 \mathrm{mg} \mathrm{NO}{ }_{3} \mathrm{~N} / \mathrm{kg}\right)$.

Within the main plots 5-5 subplots (small plots) were formed, which - in the spring before sowing (27 April, 2005) - received amounts of 0, 50, 100, 150 and $200 \mathrm{~kg}$ nitrogen (factor "b") per hectare in the form of ammonium nitrate. The gross 
territory of the small plots was $8 \times 18 \mathrm{~m}=144 \mathrm{~m}^{2}$; their net territory $13.3 \times 3.9 \mathrm{~m}=$ $51.87 \mathrm{~m}^{2}$.

An early ripening variety (Spirit) of sweet corn was sown on 11 May, 2005. The harvest, carried out by hand, took place on 1-2 August. Corn ears were measured,
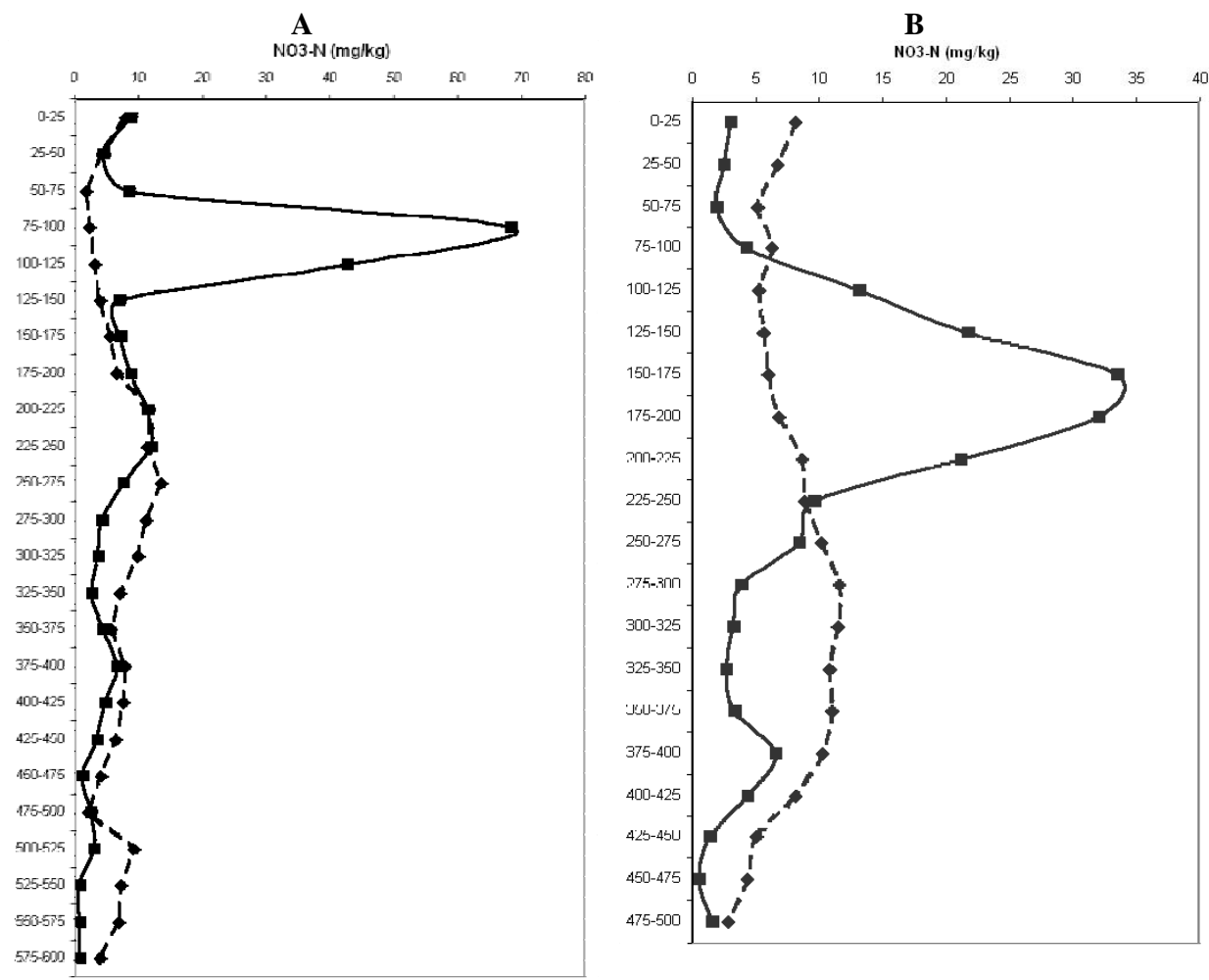

Fig. 1

Nitrate content of the soil (0-600 cm) in the spring (A) and autumn (B) of 2005

Treatments: no fertilization (dotted line); $450 \mathrm{~kg} \mathrm{~N} / \mathrm{ha}$ (continuous line)

and 40 ears were picked per plot. The percentage rate of the corn husks and grains, the grains and corn cob, the grain moisture and composition of grains were defined based on the sample.

On the plots receiving no fertilization and the highest fertilizer dose the nitrate content of the soil was measured from every $25 \mathrm{~cm}$ down to $6 \mathrm{~m}$. It was found that the majority of $\mathrm{NO}_{3}-\mathrm{N}$ accumulated at the depths of $75-125$ and also $75-280 \mathrm{~cm}$ (Fig. 1).

The nitrate content and the moisture of the soil were studied in accordance with Hungarian standards: MSZ 08-0452:1980 (1 M KCl soluble 1:2.5 soil extracting relation); MSZ 08-0205:1978 (drying at $105^{\circ} \mathrm{C}$ ). 


\section{Results and Discussion}

Correlation was only found between the yield and the nitrate content of the upper $30 \mathrm{~cm}$ soil layer, so, this leads to the conclusion that the yield of sweet corn is determined even before its roots takes up nitrogen nutrient from the layer below 30 $\mathrm{cm}$.

Fig. 2 depicts the changes in the corn ear fresh mass depending on the $\mathrm{N}$ fertilizer amount and the nitrate content of the upper layer $(0-30 \mathrm{~cm})$. The results show that in the case of the soil poorly supplied with nitrogen even the highest $\mathrm{N}$ fertilizer dose (200 kg N/ha) could not achieve the same yield as on the soil well-supplied with nitrogen (4.6 mg NO $3-\mathrm{N} / \mathrm{kg}$ soil) receiving no $\mathrm{N}$ fertilizer or the smallest amount of fertilizer $(50 \mathrm{~kg} \mathrm{~N} / \mathrm{ha})$. The same was valid for the husked maize ear per hectare as well.

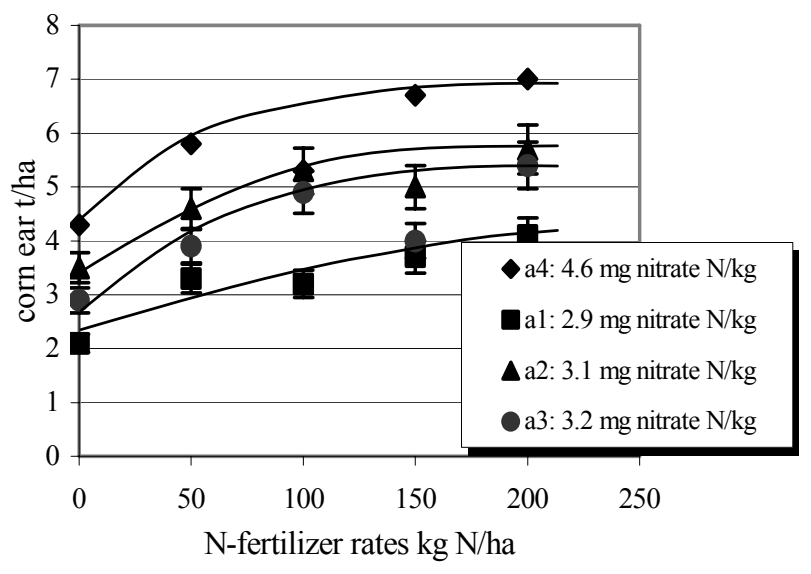

Fig. 2

Correlation between the changes in the corn ear fresh mass and the nitrate content of the soil $(0-30 \mathrm{~cm})$ and the $\mathrm{N}$ fertilizer doses in spring 2005

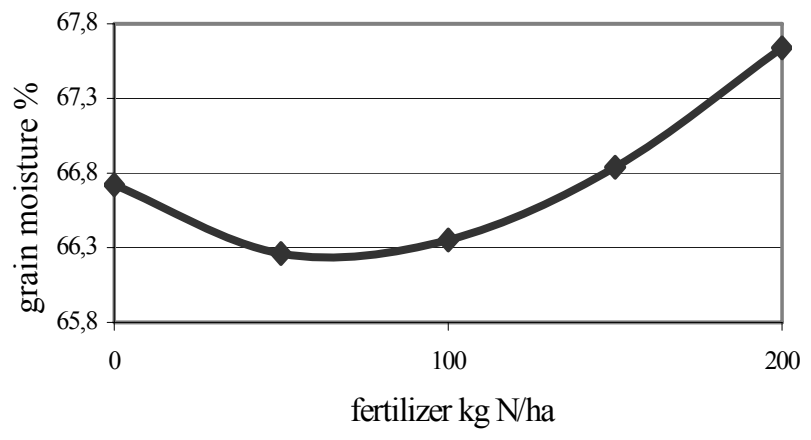

Fig. 3

Connection between corn grain moisture $\%$ and applied $\mathrm{N}$ fertilizer rates 
Based on the average of plots differently supplied with nitrogen, increasing $\mathrm{N}$ rates at the beginning reduced, but later significantly increased the moisture content of the corn (Fig. 3). On the contrary, corn grain moisture decreased with increasing pre-sowing nitrate content of the upper layer of the soil (Fig. 4).

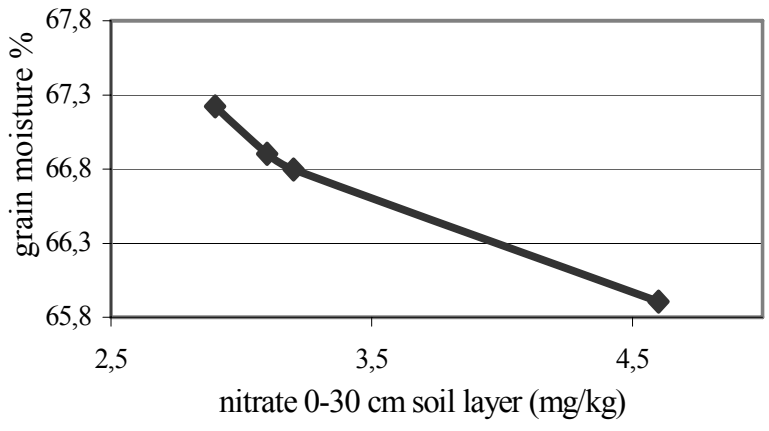

Fig. 4

Connection between corn grain moisture $\%$ and the nitrate content of the soil $(0-30 \mathrm{~cm})$

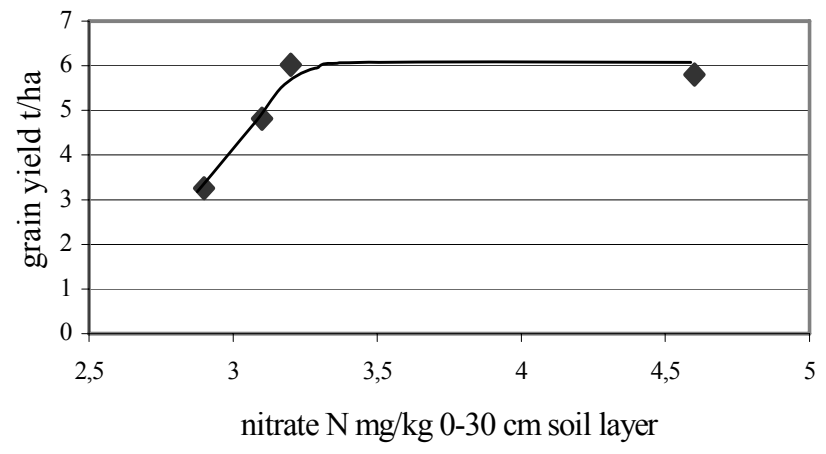

Fig. 5

Connection between corn yield and the nitrate content of the soil $(0-30 \mathrm{~cm})$

Fig. 5 shows that grain yield per hectare does not grow based on the average of $\mathrm{N}$ fertilizer, if the $\mathrm{N}$ supply is higher than $3.2 \mathrm{mg} \mathrm{NO} 3-\mathrm{N} / \mathrm{kg}$.

When taking over the sweet corn (at the cannery) the corn husks' percentage, the rate of the grain and cob, as well as the grain moisture of the corn are measured, i.e. payment is made on the basis of the rate of grain and dry matter. Therefore, it is wiser to calibrate on the rate of grain and dry matter rather than the complex index expressing the quantity and quality of the yield. Fig. 6 shows that the grain dry matter rate - contrary to the grain yield - based on the average of $\mathrm{N}$ fertilizer, actually increases up to a soil nitrogen content of $5 \mathrm{mg} \mathrm{NO}-\mathrm{N} / \mathrm{kg}$.

The calibration curves in Fig. 7 show the grain dry matter yield expected in the 2.9-4.6 $\mathrm{mg} \mathrm{NO}-\mathrm{N} / \mathrm{kg}$ soil range, on soils having various nitrogen supplies, applying 0-200 kg nitrogen fertilizer in spring. Depending on the $\mathrm{NO}_{3}-\mathrm{N}$ content of the 


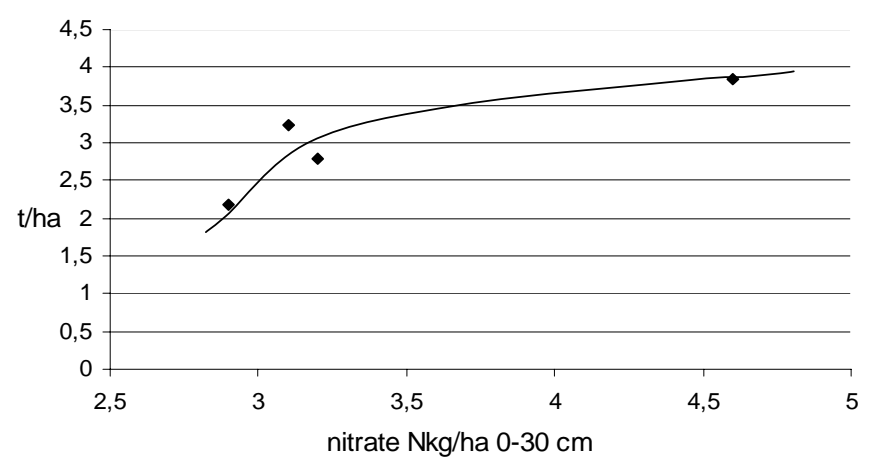

Fig. 6

Correlation between grain dry matter yield and the nitrate content of the $0-30 \mathrm{~cm}$ soil layer

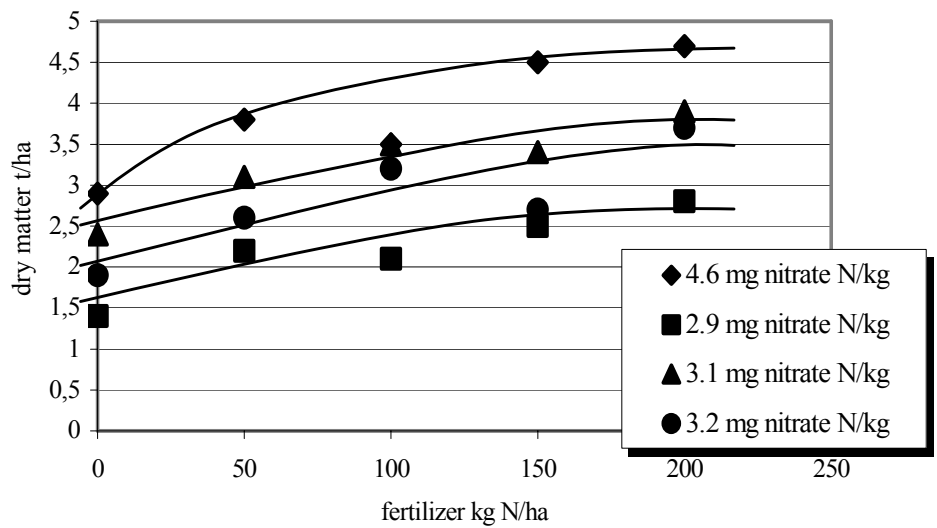

Fig. 7

Calibration curves for dry matter yields expected in soils having different nitrate contents prior to fertilization, applying 0-200 kg nitrogen fertilizer in spring 2005

soil prior to fertilization, the maximal grain dry matter rate gained with nitrogen fertilization can vary. The same yield was achieved in case the soil's nitrogen concentration was $2.9 \mathrm{mg} \mathrm{NO}-\mathrm{N} / \mathrm{kg}$ soil and the largest amount of fertilizer $(200 \mathrm{~kg}$ $\mathrm{N} / \mathrm{ha}$ ) was used, as when no fertilizer was applied at the $4.6 \mathrm{mg} \mathrm{NO}_{3}-\mathrm{N} / \mathrm{kg}$ starting nitrogen concentration of soil. Consequently it is insufficient to give only one calibration curve. The soil with poor initial nitrogen supply is not expected to achieve maximal grain dry matter rate.

The phenomenon that in the case of different soils the maximal yield achievable with fertilization is higher on soils having good production features than on soils with worse features, is well-known. The fact that in the case of the same soils that only differ from each other in calibrating soil test values this is also possible was expected after the calibration experiments conducted by NÉMETH and BUZÁs (1991) with winter oilseed rape, later on by Kulcsár with beet root (cited in BUZÁs, 2002), but, it has not been proven in sweet corn experiments yet. 


\section{Summary}

It was found that quantitative and qualitative indices of the sweet corn yield correlate with the nitrate nitrogen content of the upper soil layer $(0-30 \mathrm{~cm})$. As no correlation was established between the nitrate nitrogen content of the lower layers and the sweet corn, the conclusion was drawn that the quantity of sweet corn yield is determined even before its roots reach deeper down than $30 \mathrm{~cm}$ and the nitrogen content of the lower layers could affect the sweet corn.

Depending on the $\mathrm{NO}_{3}-\mathrm{N}$ content of the soil before fertilization the maximal corn ear mass achievable with fertilization may vary. In the study the same yield could not be accomplished in the case of the lowest soil nitrogen concentration (2.9 $\mathrm{mg} \mathrm{NO}-\mathrm{N} / \mathrm{kg})$ with the highest fertilizer rate $(200 \mathrm{~kg} \mathrm{~N} / \mathrm{ha})$ - but probably irrespective of any amount of fertilizer - as on the soil of $4.6 \mathrm{mg} \mathrm{NO}-\mathrm{N} / \mathrm{kg}$. In the case of the poorly supplied soil the fertilization curve becomes flat sooner or turns negative. The phenomenon that, regarding various soils, the maximal yield achievable on soils with good production features with fertilization is higher than in the case of soils having worse features, is well-known. That this fact is also valid in the case of the same soils was expected after calibration experiments carried out with winter oilseed rape and beet root, but it has not been proven for sweet corn as yet.

The results also showed that the grain dry matter production of sweet corn per hectare can still be enhanced with the increase in the soil's nitrogen supply, even if the corn ear does not grow.

The presented calibration curves show - in the range of $2.9-4.6 \mathrm{mg} \mathrm{NO}-\mathrm{N} / \mathrm{kg}$ soil - how much corn ear and grain dry matter produce are expected on soils with differing nitrogen supply, distributing $0-200 \mathrm{~kg}$ nitrogen fertilizer in spring.

Key words: soil nitrate-test, calibration, sweet corn, nitrogen fertilizer requirement

\section{References}

AntAL, J. et al., 1979. Directives of Fertilization and Calculation Methods on Farm Level. Part 1. Directives for N, P and K Fertilization. (In Hungarian) (Eds.: BuZÁs I. et al.) 1-47. MÉM Növényvédelmi és Agrokémiai Központ, Budapest.

BuZÁs, I., 1987. Introduction into Practical Agrochemistry. (In Hungarian) Mezőgazd. Kiadó. Budapest.

BuZÁs, I., 2002. Fertilization recommendation system and fertilization experiments. In: Proc. Meeting on Actual Problems of Agrochemistry. (In Hungarian) 129-148. DE Agrártud. Centrum. Debrecen.

NÉMETH, T. \& BUZÁS, I., 1991. Calibration N fertilization experiment with winter oilseed rape. (In Hungarian) Agrokémia és Talajtan. 40. 409-418. 